\title{
A GESTÃO DOS PROGRAMAS MAIS EDUCAÇÃO E ESCOLA A TEMPO INTEIRO: UMA ANÁLISE DE POLÍTICAS PARA EDUCAÇÃO EM TEMPO INTEGRAL
}

\author{
LA GESTIÓN DE LOS PROGRAMAS MAIS EDUCACAO Y ESCOLA A \\ TEMPO INTEIRO: UN ANÁLISIS DE POLÍTICAS PARA EDUCACIÓN EN \\ TIEMPO INTEGRAL
}

\author{
THE MANAGEMENT OF PROGRAMS MAIS EDUCAÇÃO E ESCOLA A \\ TEMPO INTEIRO: AN ANALYSIS OF POLICIES FOR FULL-TIME \\ EDUCATION
}

\author{
Elisangela Maria Pereira SCHIMONEK ${ }^{1}$ \\ Theresa ADRIÃO ${ }^{2}$
}

RESUMO: O presente estudo busca promover uma análise de dois programas governamentais para a educação em tempo integral no Brasil (Programa Mais educação) e Portugal (Programa Escola a Tempo Inteiro), com foco na gestão de ambos, tanto em âmbito de sistema como escolar, observando a abrangência e organização dos mesmos, os objetivos declarados, os atores mobilizados e as fontes de recursos. O Programa Mais Educação (PME) foi destinado às escolas de baixo Ideb e/ou situadas em regiões de vulnerabilidade social e promoveu a seleção dos educandos segundo critérios definidos em seus documentos oficiais. O Programa Escola a Tempo Inteiro (PETI) contemplou todas as escolas/ educandos de Portugal Continental de $1 .^{\circ}$ ciclo $\left(1 .^{\circ}\right.$ ao $4 .^{\circ}$ ano) do ensino básico. Trata-se de um estudo qualitativo, apoiado em revisão bibliográfica e análise documental de fontes primárias (legislações, documentos e publicações oficiais) e secundárias, que demonstrou a existência de dois Programas com organizações diferenciadas, mas com o mesmo propósito: incidir sobre as desigualdades educacionais, como meio de garantir a melhoria dos resultados educacionais obtidos em avaliações externas, admitindo, para tanto, a presença do setor privado no compartilhamento de ações de educação em tempo integral. O recorte temporal utilizado para a análise do PME e PETI foi 2008-2013.

PALAVRAS-CHAVE: Escola a tempo inteiro. Educação integral. Gestão educacional.

RESUMEN: El presente estudio tiene el objetivo de promover un análisis de dos programas gubernamentales para la educación en tiempo integral en Brasil (Programa Mais Educação) y en Portugal (Programa Escola a Tempo Inteiro), con enfoque en la gestión de ambos, tanto en el ámbito de sistema como en el escolar, observando su alcance y organización, los objetivos declarados, los actores movilizados y las fuentes

\footnotetext{
1 Universidade Estadual de Campinas (Unicamp), Campinas - SP - Brasil. Doutora em Educação (Unicamp). E-mail: lis.schimonek@gmail.com.

${ }^{2}$ Universidade Estadual de Campinas (Unicamp), Campinas - SP _ Brasil. Professora Livre Docente da Faculdade de Educação da Universidade Estadual de Campinas e do Programa de Pós-Graduação em Educação. E-mail: theadriao@gmail.com.
} 
de recursos. El Programa Mais Educação (PME) se destinó a las escuelas con bajo Ideb y/o ubicadas en regiones de vulnerabilidad social y promovió la selección de los educandos según criterios definidos en sus documentos oficiales. El Programa Escola a Tempo Inteiro (PETI) contempló todas las escuelas/educandos de Portugal Continental de $1 .^{\circ}$ ciclo $\left(1 .^{\circ}\right.$ a $4 .^{\circ}$ año) de la enseñanza básica. Se trata de un estudio cualitativo, apoyado en revisión de bibliografía y análisis documental de fuentes primarias (legislaciones, documentos y publicaciones oficiales) y secundarias, que ha demostrado la existencia de dos Programas con organizaciones diferenciadas, pero con el mismo propósito: incidir sobre las desigualdades educacionales como medio de garantizar la mejoría de los resultados educacionales obtenidos en evaluaciones externas, admitiendo, para tanto, la presencia del sector privado en el intercambio de acciones de educación en tiempo integral. El recorte temporal utilizado para el análisis del PME y el PETI fue 2008-2013.

PALABRAS CLAVE: Escuela a tiempo completo. Educación integral. Gestión educacional.

ABSTRACT: The present study aims to promote an analysis of two government programs for full-time education in Brazil (Programa Mais Educação) and Portugal (Programa Escola a Tempo Inteiro), focusing on their management, both in the system and in the school setting, observing their scope and organization, stated objectives, actors mobilized and sources of resources. The Programa Mais Educação (PME) was aimed at low Ideb schools and / or located in regions of social vulnerability and promoted the selection of the learners according to criteria defined in their official documents. The Programa Escola a Tempo Inteiro (PETI) included all primary schools and students from Continental Portugal in the 1st cycle (1st to 4th grade) of elementary education. This is a qualitative study, supported by bibliographic review and documentary analysis of primary (legislations, documents and official publications) and secondary sources, which demonstrated the existence of two Programs with differentiated organizations, but with the same purpose: to act on educational inequalities, as a means of guaranteeing the improvement of the educational results obtained in external evaluations, admitting, to this end, the presence of the private sector to share actions of full-time education. The time cut used for the analysis of PME and PETI was 2008-2013.

KEYWORDS: Full-time School. Integral education. Educational management.

\section{Introdução}

A busca pela diminuição das desigualdades educacionais tem sido recorrente em agendas políticas nacionais e internacionais e a superação destas propagadas como condição para o desenvolvimento econômico e ampliação do direito à educação. Tal preocupação adquire relevância especialmente nos países mais pobres, onde a magnitude dos problemas e desafios sociais, econômicos e educacionais é crescente e

RPGE - Revista on line de Política e Gestão Educacional, Araraquara, v. 22, n. esp.1, p. 223-243, mar., 2018. 
nos quais a educação é mais fortemente associada aos mecanismos de desenvolvimento (SCHIMONEK, 2017).

É nesta chave de compreensão que se inscrevem os Programas Mais Educação e Escola a Tempo Inteiro, uma vez que a educação em tempo integral, tornou-se uma saída para equalizar desigualdades sociais e educacionais.

Ainda que a escola seja o lócus privilegiado para políticas e programas dessa natureza, é certo que justamente nos países pobres ou de economias não centrais, a escola e, por conseguinte, a educação ofertada carecem de condições objetivas para o cumprimento de suas funções. Não por acaso, as agências multilaterais identificam a ineficiência dos sistemas educativos no cumprimento dessas tarefas e orientam a promoção de reformas educativas, dentre as quais a educação em tempo integral associada a ranquiamentos por desempenho acadêmico a partir de resultados obtidos em avaliações externas (nacionais e internacionais) (JESUS; BORGES, 2016).

Países como Brasil e Portugal apostaram em políticas de ampliação do tempo escolar como mecanismo para atacar as desigualdades educacionais e atender a uma demanda social, sobretudo das famílias mais pobres, relacionada à promoção da "guarda" de seus filhos.

No primeiro caso tratou-se do Programa federal Mais Educação (PME) e, no caso português, do Programa Escola a tempo Inteiro (PETI). Ambos declaravam-se como oportunidades para a melhoria do sucesso escolar dos educandos, traduzido na melhoria dos resultados educacionais, concomitantemente, incidiriam sobre a minimização da pobreza e da vulnerabilidade social (SCHIMONEK, 2017).

Para a realização de ambos os Programas, concebidos como medidas de proteção social com foco na diminuição das desigualdades educacionais, Brasil e Portugal previram a participação de atores sociais de natureza privada, como Organizações não Governamentais (ONGs), Instituições Particulares de Solidariedade Social (IPSS), igrejas, instituições de setores públicos e privados, voluntários, etc.

Considerando o caso brasileiro e português, apesar do protagonismo do Estado na regulação das políticas, para Pastorini (2002), percebe-se a transferência de responsabilidades de sua execução para a sociedade civil e para o terceiro setor.

O envolvimento da sociedade civil na oferta e gestão de políticas sociais, como a educação, operacionaliza o modelo de governança assentado na presença direta do setor privado na execução das políticas, impulsionado inclusive pela OCDE. 
Segundo o documento VENTURE PHILANTHROPY IN DEVELOPMENT de 2014, desde 2012 a OCDE instituiu uma rede global, vinculada ao Centro de Desenvolvimento da própria OCDE, constituída por um pequeno grupo de fundações que integram duas frentes de trabalho. A primeira frente relacionada à filantropia empresarial, a segunda a inovações desenvolvidas por filantropos. Para a OCDE, o quadro de recessivo dos países da zona do Euro e a consequente diminuição dos fundos públicos para a promoção do desenvolvimento em países pobres, exigiria a participação mais direta desses grupos privados e de sua "expertise" e recursos (ADRIÃO, 2017, p.19).

Assim, políticas e programas são formulados considerando e pressupondo a presença do setor privado em sua execução.

Os programas aqui analisados, do ponto de vista de seu desenho, exemplificam as condições acima indicadas: atendem a demandas sociais por meio da atuação direta de agentes do setor privado, seja na qualidade de pessoa jurídica ou de pessoa física, custeados por fundos públicos e se justificam como mecanismo para a diminuição das desigualdades educacionais.

O objetivo deste artigo é apresentar e problematizar mecanismos de gestão, previstos nos dois programas, com destaque para aqueles que induzem a presença do setor privado.

Com Paro (2000, 2011), entende-se que gestão e administração são tomados como equivalentes em seu sentido geral: tomada de decisão sobre recursos e processos mais adequados para os objetivos educacionais estabelecidos, de modo que a privatização da gestão da educação pública refere-se à subordinação ao setor privado dos processos relativos à definição dos meios e dos fins desta educação.

$\mathrm{O}$ texto assenta-se em pesquisa de natureza documental em fontes primárias e secundárias e organiza-se em 4 partes. Na primeira e terceira parte, apresentam-se as peculiaridades e organização dos programas PME e PETI. Na segunda e quarta parte reflete-se sobre a gestão dos Programas, destacando a presença do setor privado na oferta da educação em tempo integral. Para concluir, estabelecemos um diálogo entre ambos os Programas, apontando algumas divergências e similaridades.

\section{O Programa Mais Educação (Brasil)}

O PME, implantado em escolas brasileiras, foi instituído pela Portaria Interministerial n. ${ }^{\circ}$ 17/2007 e regulamentado pelo Decreto n. ${ }^{\circ} 7.083 / 2010$, vigorando

RPGE - Revista on line de Política e Gestão Educacional, Araraquara, v. 22, n. esp.1, p. 223-243, mar., 2018. 
até $2016^{3}$. Vinculou-se ao Plano de Desenvolvimento da Educação (PDE), este lançado em 2007 no governo do presidente Luiz Inácio Lula da Silva. Muitas das ações do PDE, dentre elas o PME, foram fomentadas por meio da transferência de verbas e da realização de assistência técnica por parte do Ministério da Educação aos entes federados que aderiram ao Plano de Metas Compromisso Todos pela Educação, condição que exigia o cumprimento das 28 diretrizes constantes do referido Plano (BRASIL, 2009)

Para tanto, o governo federal instituiu uma sistemática de planejamento e de indução de políticas aos entes federados subnacionais, o Plano de Ações Articuladas (PAR), por meio do Decreto n. ${ }^{\circ}$ 6.094/2007:

Art. 9. ${ }^{\circ}$ O PAR é o conjunto articulado de ações, apoiado técnica ou financeiramente pelo Ministério da Educação, que visa o cumprimento do Compromisso e a observância das suas diretrizes.

Art. 10 O PAR será a base para o termo de convênio ou cooperação, firmado entre o Ministério da Educação e o ente apoiado (BRASIL, 2007a)

O PAR tornou-se um dos principais instrumentos de gestão, monitoramento e acompanhamento das ações dos entes federados pelo Ministério da Educação (MEC), dentre as quais o PME, cujos objetivos declarados eram melhorar resultados educacionais e promover um ensino de qualidade. Tratou-se de uma estratégia de indução à ampliação da jornada escolar dos educandos, promovendo a organização curricular por meio da oferta de atividades socioeducativas (oficinas) ofertadas no contraturno escolar (BRASIL, 2013).

Por meio do Artigo $1 .^{\circ}$ da Portaria Interministerial n. ${ }^{\circ}$ 17/2007, o PME demonstrou a intenção de:

Contribuir para a formação integral de crianças, adolescentes e jovens, por meio da articulação de ações, de projetos e de programas do Governo Federal e suas contribuições às propostas, visões e práticas curriculares das redes públicas de ensino e das escolas, alterando o ambiente escolar e ampliando a oferta de saberes, métodos, processos e conteúdos educativos (BRASIL, 2007b).

${ }^{3}$ Em 2017, no governo Michel Temer, o PME passou a intitular-se Programa Novo Mais Educação, sendo reformulado quanto aos critérios de seleção das escolas e estudantes, carga horária, foco em atividades de reforço escolar, ausência de recursos para investimento em capital (material permanente), etc.

RPGE - Revista on line de Política e Gestão Educacional, Araraquara, v. 22, n. esp.1, p. 223-243, mar., 2018. 
Destinou-se, inicial e prioritariamente, às escolas de baixo Ideb (Índice de Desenvolvimento da Educação Básica) localizadas em regiões marcadas pela vulnerabilidade social, por requererem a convergência de políticas públicas. Ao longo dos anos de sua implantação foram agregados outros critérios se seleção, como as escolas que possuíam um significativo número de educandos contemplados com o Programa Bolsa Família (BRASIL, 2013).

Rosa (2012) considera o PME como mecanismo de luta contra a pobreza, a exclusão social e a marginalização cultural, apostando na ampliação de tempos e espaços educativos como meio para garantir a melhoria da qualidade do ensino público.

No período de 2008, primeiro ano de vigência do PME, a 2013, identifica-se o crescimento no número de escolas com o PME, conforme Gráfico 1:

Gráfico 1: Evolução do número de escolas (Ensino Fundamental I e II) que aderiram ao Programa Mais Educação (2008-2013)

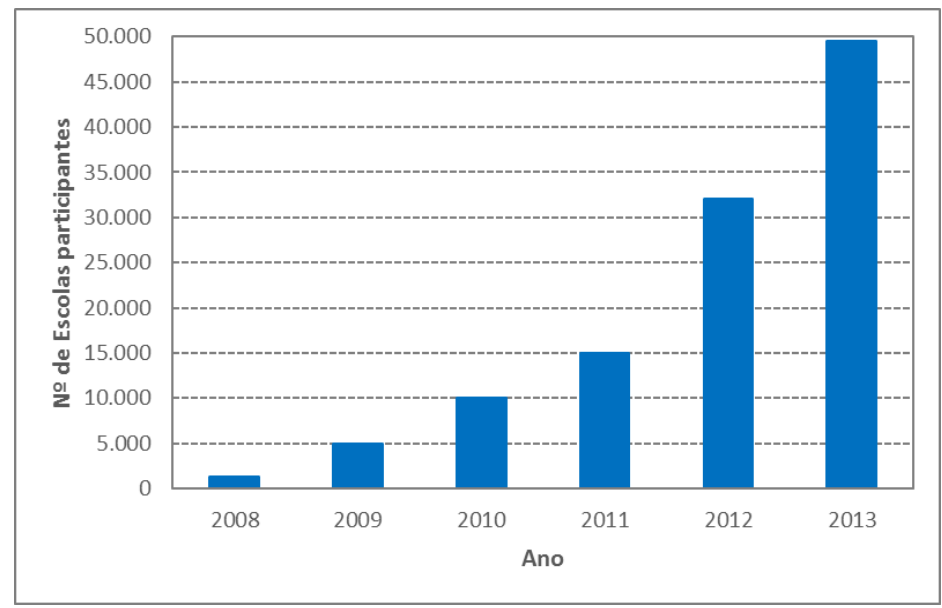

Fonte: Schimonek (2015, p. 1105) .

Em 2008 o PME atendeu 271.939 educandos e em 2013 a 7.198 .208 matrículas, o que de fato confirmou o PME, como uma política de indução à implantação da jornada ampliada.

Alinhado ao estabelecido pela Lei de Diretrizes e Bases da Educação Nacional (Lei n. ${ }^{\circ}$ 9394/96), o Programa ampliou a jornada escolar de algumas escolas públicas para no mínimo $7 \mathrm{~h}$ de funcionamento diário, sendo as atividades socioeducativas ministradas por monitores/oficineiros voluntários (BRASIL, 2010).

${ }^{4}$ Com base em: <http://portal.inep.gov.br/basica-censo-escolar-sinopse-sinopse>. 
Entretanto, ao direcionar o atendimento prioritário às escolas de baixo Ideb, o Mec reforçou a preocupação com a melhoria dos resultados educacionais, compreendendo a superação dos índices deficitários obtidos em avaliações externas, como forma de diminuição das desigualdades educacionais.

Além de o PME apresentar o objetivo de favorecer a diminuição das desigualdades educacionais, o Artigo $3 .^{\circ}$ do Decreto n. ${ }^{\circ}$ 7083/2010 especificou outras finalidades deste:

I - formular política nacional de educação básica em tempo integral; II - promover diálogo entre os conteúdos escolares e os saberes locais; III - favorecer a convivência entre professores, alunos e suas comunidades; IV - disseminar as experiências das escolas que desenvolvem atividades de educação integral; e V - convergir políticas e programas de saúde, cultura, esporte, direitos humanos, educação ambiental, divulgação científica, enfrentamento da violência contra crianças e adolescentes, integração entre escola e comunidade, para o desenvolvimento do projeto político-pedagógico de educação integral (BRASIL, 2010).

Para efeito do objetivo deste artigo, destaca-se que, apoiado no Inciso III do Decreto relativo à valorização dos saberes advindos da comunidade, o PME operou em sua imensa maioria por meio da "contratação" de voluntários.

A portaria interministerial n. ${ }^{\circ} 17 / 2007$, em seu Art. $6 .^{\circ}$ do capítulo III "Das diretrizes para o apoio a projetos e ações", também apelou para o envolvimento da sociedade ao enfatizar que,

O PME visa fomentar, por meio de sensibilização, incentivo e apoio, projetos ou ações de articulação de políticas sociais e implementação de ações socioeducativas oferecidas gratuitamente a crianças, adolescentes e jovens e que considerem as seguintes orientações: [...] VI. fomentar a participação das famílias e comunidades nas atividades desenvolvidas, bem como da sociedade civil, de organizações não governamentais e esfera privada (BRASIL, 2007b).

Assim, o PME, além de se constituir como uma ação interministerial, intergovernamental e intersetorial, pressupõe o engajamento da sociedade civil, de ONGs e do setor privado em geral para sua consecução. Efetivamente, coube aos municípios e aos estados articularem-se para o cumprimento das diretrizes do Programa, acionando cada qual em seu próprio âmbito, outros setores governamentais.

Para além da realização das atividades do PME, propriamente ditas, o inciso III do Art. $8^{\circ}$ da mesma Portaria, indica que o conjunto da comunidade escolar (famílias, 
vizinhos etc.) devem envolver-se na busca por espaços alterativos para a realização do Programa: "mobilizar e estimular a comunidade local para a oferta de espaços buscando sua participação complementar em atividades e outras formas de apoio que contribuam para o alcance das finalidades do Programa" (BRASIL, 2009, p. 16).

Adrião e Peroni (2005, p. 9) consideram que no Brasil, as demandas educacionais, em especial as não contempladas pelas etapas da obrigatoriedade ${ }^{5}$, para a qual o dever do Estado é explicito, passaram a ser atendidas privadamente por atores sociais atomizados: instituições educacionais privadas, ONGs, empresas, grupos comunitários locais ou de interesse específico, igrejas e outros grupos, que vem usufruindo, inclusive, de subvenção pública.

Cavaliere (2014) alerta para os problemas decorrentes do trabalho voluntário em escolas que implementaram o PME:

Devido à condição precária desse vínculo de trabalho, a rotatividade desses agentes é alta, especialmente nos grandes centros, o que agrava ainda mais as dificuldades de integração das atividades por eles conduzidas com as atividades da escola. Salvo exceções, há pouco contato entre eles e os professores. Em locais onde há distribuição de bônus pelo bom desempenho da escola, prática cada vez mais comum nos sistemas públicos de educação, os monitores, não tendo vínculos efetivos, ficam de fora[...] (CAVALIERE, 2014, p. 1216).

Se, por um lado, as escolas poderiam conseguir voluntários com perfis adequados ao atendimento de educandos em tempo integral que permitisse romper com a ideia de mais escolarização, por outro sujeitam-se à interrupção dos projetos, dada a falta de vínculo empregatício e baixa remuneração, fato que acarreta dificuldade de articulação entre as atividades desenvolvidas nos dois turnos e fundamentalmente, as escolas submetem-se às limitações determinadas por sua localidade: escolas em regiões de vulnerabilidade social e econômica podem também carecer de alternativas.

Cavaliere (2014, p. 1217) destacou que a proposta do PME inspirou-se no movimento das cidades educadoras, partindo da "compreensão da cidade como lócus educativo, a requerer a presença constante e intensiva dos estudantes nos espaços públicos, bem como a troca e sinergia entre a escola e seu entorno". Para essa perspectiva, as

${ }^{5}$ Como a educação em tempo integral, cuja oferta vem sendo objeto de contratos/ convênios com o setor privado.

RPGE - Revista on line de Política e Gestão Educacional, Araraquara, v. 22, n. esp.1, p. 223-243, mar., 2018. 
[...] parcerias são outro elemento forte no PME, associadas ou não ao conceito das cidades educadoras. Nas condições dadas, quando se obtêm parcerias com instituições locais visando o uso de seus espaços, a precariedade das instalações e das vias urbanas e a impropriedade em se utilizar templos religiosos - quase sempre as únicas instituições existentes além da própria escola - emperram ou desvirtuam o desenvolvimento desse tipo de alternativa (CAVALIERE, 2014, p. 1217).

A maioria das escolas aderentes ao PME localizavam-se nas periferias e em regiões de vulnerabilidade social, vivenciando as contradições indicadas pela autora, em verdade, "mais frequentemente se dá a situação contrária na qual o prédio escolar é o único equipamento público disponível, sendo utilizado para outras finalidades de interesse coletivo das comunidades" (CAVALIERE,2014, p. 1217).

\section{A gestão do Programa Mais Educação}

Enquanto o Mec assumiu a função de proposição e regulação da política de educação em tempo integral (PME), inclusive por meio do envio de recursos financeiros para a sua implantação, a execução do Programa foi descentralizada para secretarias de educação e escolas, estaduais e municipais. As Secretarias, ainda sob orientação do Ministério, indicaram um coordenador para acompanhar a implantação do PME, o que, no caso daquelas mais estruturadas envolvia orientações, acompanhamento pedagógico e de execução financeira.

Em âmbito escolar, o Mec prescreveu a necessidade de disponibilização de um professor comunitário ${ }^{6}$ pela Secretaria Municipal ou Estadual de Educação como contrapartida ao aporte de recursos efetuados pelo FNDE/ Mec diretamente às unidades escolares. Tal professor assumiu a responsabilidade de organizar o currículo, orientar e acompanhar o trabalho dos voluntários, buscar parceiros, estabelecer diálogo com a comunidade, viabilizar espaços para as atividades do PME, etc.

Para fazer jus ao recurso financeiro, a escola selecionada para o PME deveria incluir no Sistema Integrado de Monitoramento Execução e Controle (Simec), do governo federal, um Plano contendo as oficinas/atividades para o período de dez meses letivos, o número de alunos a atender e os espaços para o funcionamento do Programa. Somente após a validação do Plano pelas Secretarias de Educação e sua aprovação pelo $\mathrm{Mec}$, os recursos financeiros eram destinados às escolas, em conta corrente da unidade

${ }^{6}$ Trata-se de um profissional de carreira que assume o papel de coordenador escolar do PME.

RPGE - Revista on line de Política e Gestão Educacional, Araraquara, v. 22, n. esp.1, p. 223-243, mar., 2018. 
executora. O Simec, associado ao PAR, constituiu-se, em uma plataforma para o monitoramento das ações implantadas pela escola.

Os recursos financeiros, repassados diretamente às escolas, deveriam ser empregados na aquisição de materiais permanentes (capital) e de consumo (custeio), além do ressarcimento de despesas com transporte e alimentação dos voluntários responsáveis pelo desenvolvimento das atividades do PME.

A tabela 1 indica os valores repassados para aplicação na categoria custeio, informamos os valores recebidos pelas escolas, no período de 2008 a 2013:

Tabela 1: Repasse mensal dos valores nominais do PDDE/Integral para custeio (2008-2013) - Programa Mais Educação

\begin{tabular}{|c|c|c|c|c|c|c|}
\hline $\begin{array}{l}\text { Número de } \\
\text { Estudantes }\end{array}$ & $\begin{array}{c}\text { Valor em } \\
\text { custeio } \\
2008\end{array}$ & $\begin{array}{c}\text { Valor em } \\
\text { custeio } \\
2009\end{array}$ & $\begin{array}{c}\text { Valor em } \\
\text { custeio } \\
2010\end{array}$ & $\begin{array}{c}\text { Valor em } \\
\text { custeio } \\
2011\end{array}$ & $\begin{array}{c}\text { Valor em } \\
\text { custeio } \\
2012\end{array}$ & $\begin{array}{c}\text { Valor em } \\
\text { custeio } \\
2013\end{array}$ \\
\hline Até 500 & $\mathrm{R} \$ 500,00$ & $\mathrm{R} \$ 500,00$ & $\mathrm{R} \$ 500,00$ & $\mathrm{R} \$ 400,00$ & $\mathrm{R} \$ 400,00$ & $\mathrm{R} \$ 300,00$ \\
\hline 501 a 1000 & $\mathrm{R} \$ 1000,00$ & $\mathrm{R} \$ 1000,00$ & $\mathrm{R} \$ 1000,00$ & $\mathrm{R} \$ 800,00$ & $\mathrm{R} \$ 800,00$ & $\mathrm{R} \$ 600,00$ \\
\hline 1001 a 1500 & $\mathrm{R} \$ 1500,00$ & $\mathrm{R} \$ 1500,00$ & \multirow{3}{*}{$\mathrm{R} \$ 1500,00$} & \multirow{3}{*}{$\mathrm{R} \$ 1200,00$} & \multirow{3}{*}{$\mathrm{R} \$ 1200,00$} & \multirow{3}{*}{$\mathrm{R} \$ 700,00$} \\
\hline 1501 a 2000 & $\mathrm{R} \$ 2000,00$ & $\mathrm{R} \$ 2000,00$ & & & & \\
\hline Acima de 2000 & $\mathrm{R} \$ 2500,00$ & $\mathrm{R} \$ 2500,00$ & & & & \\
\hline
\end{tabular}

Fonte: Elaboração das próprias autoras, com base nos Manuais Operacionais do PME.

Analisando a tabela acima, nota-se um decréscimo nos valores destinados à categoria custeio entre 2010/ 2011 e 2012/ 2013. Observa-se mudanças nos agrupamentos estabelecidos em função dos matriculados no PME: entre 2008 e 2009 haviam cinco intervalos; entre 2010 e 2013 os agrupamentos concentraram-se em três faixas: até 500, de 501 a 1000 e de 1001 a acima de 2000, na prática esta concentração redundou numa significativa diminuição de recursos financeiros, sobretudo para as escolas com maior número de educandos.

A partir de 2011, o PME também previu a descentralização de recursos para a aplicação na categoria capital para aquisição de materiais permanentes, conforme Tabela 2:

Tabela 2: Repasse mensal dos valores nominais do PDDE/Integral para bens de capital - Programa Mais Educação (2011-2013)

\begin{tabular}{|c|c|c|c|}
\hline Número de Estudantes & Valor 2011 & Valor 2012 & Valor 2013 \\
\hline Até 500 & $\mathrm{R} \$ 100,00$ & $\mathrm{R} \$ 100,00$ & $\mathrm{R} \$ 100,00$ \\
\hline
\end{tabular}

RPGE - Revista on line de Política e Gestão Educacional, Araraquara, v. 22, n. esp.1, p. 223-243, mar., 2018. 


\begin{tabular}{|c|c|c|c|}
\hline 501 a 1000 & $\mathrm{R} \$ 200,00$ & $\mathrm{R} \$ 200,00$ & $\mathrm{R} \$ 200,00$ \\
\hline 1001 a acima de 2000 & $\mathrm{R} \$ 300,00$ & $\mathrm{R} \$ 300,00$ & $\mathrm{R} \$ 200,00$ \\
\hline
\end{tabular}

Fonte: Elaboração das próprias autoras, com base nos Manuais Operacionais do PME.

No período, destaca-se que em 2013, as escolas com maior número de estudantes sofreram um corte de $50 \%$ no valor mensalmente recebido.

Tanto na categoria custeio, quanto na de capital, registra-se diminuição nos recursos financeiros repassados ao longo dos anos, indicando a intenção do governo federal de repassar os custos de manutenção do PME, de programas voltados para a ampliação da jornada escolar dos educandos aos estados e municípios.

Em relação ao "ressarcimento financeiro" dos voluntários, a Tabela 3 indica, em valores nominais, o valor mensal a ser pago a cada voluntário por turma atendida e valor máximo a que teria direito para um número também máximo de cinco turmas.

Tabela 3: Valores nominais de ressarcimento dos monitores (voluntários) do PME, em escolas urbanas e do campo (2008-2013)

\begin{tabular}{|c|c|c|c|}
\hline Anos & $\begin{array}{c}\text { Valores mensais por turma } \\
\text { monitorada }\end{array}$ & $\begin{array}{c}\text { Valor máximo pago por } \\
\text { monitor (5 turmas) }\end{array}$ & Tipo de escola \\
\hline 2008 & $\mathrm{R} \$ 48,00$ & $\mathrm{R} \$ 240,00$ & \multirow{2}{*}{$\begin{array}{c}\text { Escolas urbanas e do } \\
\text { campo }\end{array}$} \\
\hline 2009 & $\mathrm{R} \$ 60,00$ & $\mathrm{R} \$ 300,00$ & \multirow{2}{*}{ Escolas urbanas } \\
\hline 2010 & $\mathrm{R} \$ 60,00$ & $\mathrm{R} \$ 300,00$ & \multirow{2}{*}{ Escolas do campo } \\
\hline 2011 & $\mathrm{R} \$ 60,00$ & $\mathrm{R} \$ 300,00$ & \\
\hline 2012 & $\mathrm{R} \$ 60,00$ & $\mathrm{R} \$ 300,00$ & \\
\hline 2013 & $\mathrm{R} \$ 80,00$ & $\mathrm{R} \$ 600,00$ & \\
\hline 2013 & $\mathrm{R} \$ 120,00$ & $\mathrm{R} \$ 600,00$ & \\
\hline
\end{tabular}

Fonte: Elaboração das próprias autoras com base nos Manuais Operacionais de Educação Integral.

Nota-se que tanto nas escolas urbanas, como nas do campo, o maior valor mensal pago a um monitor /voluntário por 5 turmas, correspondeu em média a pouco mais que 90 U\$ até 2011. A partir de 2012, foi prevista uma diferenciação nos repasses financeiros às escolas urbanas e do campo, recebendo as últimas, valores mais altos para o pagamento dos voluntários. Em 2013 o valor máximo pago ao voluntário por 5 turmas nas escolas urbanas foi algo em torno de 120 U\$ mensais e de 180 U\$ para o das escolas do campo. $\mathrm{O}$ valor mensal pago ao voluntário por turma permaneceu estagnado no período de 2009 a 2012 (escolas urbanas) e de 2009 a 2011 (escolas do campo), 
demonstrando a precarização do trabalho de monitoria. $O$ valore repassado ao voluntário destinou-se a cobertura das despesas de alimentação e transporte.

De acordo com Lopes e Araújo (2012) a transferência de recursos não ocorreu de forma linear, havendo atrasos nos repasses, o que contribuiu para a descontinuidade das ações do PME, rotatividade dos voluntários e desarticulação curricular, pois as atividades socioeducativas (oficinas) tornaram-se desconexas do currículo formal. Tais fatores comprometeram o bom atendimento aos educandos e os resultados educacionais.

\section{O Programa Escola a Tempo Inteiro (Portugal)}

O Programa Escola a Tempo Inteiro (PETI) foi proposto pelo XVII Governo Constitucional de Portugal (2005-2009) e criado pelo Despacho n. ${ }^{\circ} 12$ 591/2006 (2. série), de 16 de Junho de 2006, tendo como Primeiro Ministro José Sócrates ${ }^{7}$ e Ministra da Educação Maria de Lurdes Reis Rodrigues ${ }^{8}$, ambos do Partido Socialista e surgiu como uma das medidas políticas para minimizar as desigualdades existentes entre os educandos.

Essa política foi implantada em Portugal Continental a partir de 2006, em todas as escolas de educação pré-escolar e $1 .^{\circ}$ Ciclo $\left(1 .^{\circ}\right.$ ao $4 .^{\circ}$ ano). O foco prioritário no $1 .^{\circ}$ Ciclo, deveu-se sobretudo a um diagnóstico governamental que indicava estarem as escolas de $1 .^{\circ}$ ciclo funcionando em estado de abandono e sem recursos educativos suficientes, condição que afetou negativamente a qualidade do serviço prestado e a oportunidade de um percurso escolar bem sucedido para os alunos, sobretudo dos meios rurais ou da periferia das grandes cidades (RODRIGUES, 2010, p. 21),

A Escola a Tempo Inteiro (ETI), já nos primeiros anos de funcionamento, possibilitou padrões de qualidade a todas as escolas e promoveu o acesso a recursos escolares e educativos de qualidade em condições de igualdade para todas as crianças (RODRIGUES, 2010).

Segundo Mouraz, Vale e Martins (2012, p. 127) a ETI surgiu como "uma resposta aos desafios que, em Portugal, a escola de massas trouxe ao sistema e que antes ainda não tinham sido experienciados, nomeadamente a constatação de que esta deve preocupar-se em assegurar a justiça social”. O PETI pretendeu diminuir a desigualdade social e educacional, contribuindo para aumentar os níveis de sucesso dos educandos na

${ }^{7}$ Permaneceu no governo de 12 de março de 2005 a 21 de junho de 2011.

${ }^{8}$ Esteve à frente do Ministério da Educação no período de 12 de março de 2005 a 26 de outubro de 2009.

RPGE - Revista on line de Política e Gestão Educacional, Araraquara, v. 22, n. esp.1, p. 223-243, mar., 2018. 
escolaridade formal, em concordância com as tendências identificadas pela Organização para a Cooperação e Desenvolvimento Econômico (OCDE) na promoção da equidade na educação (MOURAZ, VALE E MARTINS, 2012).

Com o Despacho n. ${ }^{\circ} 12.591 / 2006$, todas as escolas do ensino público, que ministravam a educação pré-escolar e o $10^{\circ}$ ciclo do ensino básico, passaram a manter-se abertas pelo menos até às $17 \mathrm{~h} 30$, ofertando aos educandos no mínimo 8 horas diárias de atividades escolares (PORTUGAL, 2006a).

O PETI pretendeu cumprir os seguintes objetivos:

1. Garantir, no espaço da escola a todos os alunos do $1 .^{\circ}$ ciclo, de forma gratuita, a oferta de cum conjunto de aprendizagens enriquecedoras do currículo e das aprendizagens;

2. Promover a articulação entre o funcionamento da escola e a organização de repostas sociais no domínio do apoio à família (PORTUGAL, 2006b, p. 4).

Além desses objetivos, duas ideias estiveram subjacentes à política de ETI: “a escola como centro das políticas educativas; a escola pública como plataforma de igualdade de oportunidades ao serviço da diminuição das desigualdades sociais" (PIRES, 2011, p. 39). Nesses termos a escola assume o protagonismo pela execução da política concebida de forma centralizada, sendo responsabilizada pela superação dos problemas educacionais. Para promover a ampliação da jornada escolar dos educandos, aumentou-se a carga horária das disciplinas do chamado núcleo duro do currículo, consubstanciando um processo de "hiperescolarização", como condição para a obtenção de melhores resultados escolares, adquiridos em avaliações externas. Paralelamente, foram ofertadas as Atividades de Enriquecimento Curricular (AEC) (PIRES, 2014, p. 65).

As AEC, gratuitas, de oferta obrigatória e matrícula facultativa, oferecidas no espaço escolar, privilegiaram o ensino do inglês e da música, a atividade física e desportiva, e foram conduzidas por profissionais habilitados (PIRES, 2011, p. 38).

No entanto, tais atividades ocuparam um espaço restrito do currículo. Conforme Artigo $9^{\circ}$, ponto 2 da Portaria n. ${ }^{\circ}$ 644-A/ 2015 "as AEC têm uma duração semanal de entre cinco a sete horas e meia, para os $1 .^{\circ}$ e $2 .^{\circ}$ anos de escolaridade, e de entre três a cinco horas e meia, para os $3 .^{\circ}$ e $4 .^{\circ}$ anos de escolaridade" (PORTUGAL, 2015).

As AEC, que essencialmente deveriam possuir uma "natureza eminentemente lúdica e cultural" (PORTUGAL, 2012), apresentam-se de forma altamente formalizada: 
de natureza disciplinar e sujeitas a orientações programáticas, potencializadoras da continuidade da "forma escolar", orientadas preferencialmente por docentes com habilitações profissionais para a docência disciplinar, sendo norteadas por regulamentações e a orientações (do centro para a periferia) coercivas e com tendência para a sua uniformização e homogeneização (PIRES, 2014, p. 68).

\section{A gestão das AEC do Programa Escola a Tempo Inteiro}

A operacionalização das AEC realizou-se por meio de entidades promotoras: as autarquias locais, associação de pais e de encarregados da educação, IPSS e agrupamento de escolas (PORTUGAL, 2006a). Quando era o agrupamento de escolas a entidade promotora, caberia ao diretor da escola realizar a seleção, o recrutamento e a contratação dos professores para a atuação nas AEC, observando se a formação/licenciatura do mesmo era compatível às AEC e faixa etária dos educandos. Quando as demais entidades foram as promotoras, essas ficavam responsáveis pela seleção dos profissionais/técnicos (não necessariamente docentes) que conduziriam as AEC, observando se a habilitação que possuíam era adequada. Com recursos oriundos do Ministério da Educação, tais entidades promotoras assumiram a responsabilidade pelo provimento de materiais e equipamentos necessários à efetivação das AEC

Segundo Faria (2010, p. 134), o Estado português chamou para si o papel regulador das competências pedagógicas, curriculares e de inspeção, e partilhou com as entidades promotoras a responsabilidade de organização do $1 .^{\circ}$ ciclo do ensino básico.

O Artigo $14^{\circ}$ do Despacho n. ${ }^{\circ} 12.591 / 2006$, admitiu a possibilidade de “constituir parcerias [...] com outras entidades públicas e privadas com ou sem fins lucrativos, para a concretização das AEC, designadamente, para a seleção e recrutamento dos profissionais que venham a assegurar o desenvolvimento das atividades".

Nesse sentido, as AEC não foram compreendidas como um serviço público a ser garantido exclusivamente pelo Estado, mas também por entidades privadas, nomeadamente IPSS, sendo proposto a:

Garantia do princípio da subsidiaridade em que serviço público não significa ter de ser prestado necessariamente, pelo sector público, podendo prioritariamente ser contratualizado com uma instituição de solidariedade social que lhe acrescente mais valor.

RPGE - Revista on line de Política e Gestão Educacional, Araraquara, v. 22, n. esp.1, p. 223-243, mar., 2018. 
Nessa perspectiva, o Estado não pode ser o "grande e único educador e a tempo inteiro" (PIRES, 2011, p. 41).

Segundo Pires (2011, p. 41), o FENPROF (Federação Nacional dos Professores) reforçou que o modelo de ETI se configurou como um incentivo a formas de privatização do currículo da escola ao promover a "adoção de lógicas empresariais e mecanismos de mercado" tornando as AEC uma "porta de entrada dos privados na escola pública”.

Segundo Pires (2014) o PETI atribuiu uma clara e intencional preferência que as autarquias tornassem entidades promotoras dessa política, numa perspectiva de aparente descentralização das ofertas educativas.

Com esse direcionamento muitas autarquias assumiram a responsabilidade em colocar o PETI em funcionamento, selecionando e celebrando contratos com profissionais para a condução das AEC, realizando parcerias com outros atores sociais e terceirizando serviços, garantindo as condições materiais e físicas dos agrupamentos escolares, tornando-se um órgão de controle mais próximo às escolas.

O PETI afirma-se como um exemplo significativo do modo de prestação do serviço público educativo realizado através de "contratos de ação pública” (MOURAZ, VALE, MARTINS, 2012, p. 124).

\footnotetext{
É hoje mais claro que aquela lógica de contratualização, baseada num serviço desconcentrado por contratos entre o ME e os municípios e por subcontratos entre estes e outras entidades públicas e privadas, mostra-se cada vez mais vulnerável aos condicionalismos de um mercado educativo que pretende ocupar o espaço pouco a pouco abandonado pelo Estado. Ao mesmo tempo, como consequência de crescentes limitações orçamentais e da desregulação produzida pela imensa variedade de entidades promotoras e operacionais existentes no terreno, vão-se registando alterações determinantes na gestão curricular, na organização pedagógica e até na arquitetura funcional do $1^{\circ}$ ciclo do ensino básico (MOURAZ; VALE; MARTINS, 2012, p. 125).
}

Pires (2014, p. 55) alerta para a problemática da entrada direta de entidades privadas na escola pública (numa lógica concorrencial e de mercado).

Os docentes selecionados para a condução das AEC receberam seu pró-labore (2013) pelo índice inicial de carreira profissional (índice 167), ou seja, 1.500,00€ por uma jornada de 35 horas semanais. Já os técnicos habilitados escolhidos foram pagos diretamente pelas entidades promotoras, pelo índice 126, tendo um rendimento (2013) menor que o dos docentes em início de carreira, ou seja, 1.145,79€ por 35 horas semanais de trabalho. 
Com relação ao financiamento destinado às atividades que compõem o Programa Escola a Tempo Inteiro, o Artigo 20, ponto 1 da Portaria n. ${ }^{\circ}$ 644-A/2015, destacou que este "consiste numa comparticipação financeira a conceder pelo Ministério da Educação às entidades promotoras" (PORTUGAL, 2015).

Para o cálculo do apoio financeiro foram considerados o número de educandos participantes e a carga horária anual das AEC, sendo que "o valor máximo da comparticipação financeira anual será de 150 euros por aluno dos $1 .^{\circ}$ e $2 .^{\circ}$ anos de escolaridade, e de 90 euros por aluno dos $3 .^{\circ}$ e $4 .^{\circ}$ anos de escolaridade" (PORTUGAL, 2015).

O Ministério da Educação também previu alguns mecanismos de controle e monitoramento do PETI. A Comissão Coordenadora, designada pelo governo português teve a função de analisar, avaliar e aprovar as "planificações e propostas de financiamento" além de acompanhar a execução das mesmas, propondo medidas necessárias para os anos posteriores. Já o acompanhamento e controle dos recursos financeiros das AEC ficaram sob a responsabilidade da "Direção Geral dos Estabelecimentos Escolares (DGEstE) (PORTUGAL, 2015).

Outra forma de controle foi realizada a partir das plataformas eletrônicas oficiais do Ministério da Educação, tendo as escolas que alimentá-las com dados sobre o PETI.

Os resultados educacionais também foram publicizados em Portugal, pelo Ministério da Educação, gerando um clima de competitividade entre as escolas, cobrança por melhores resultados e responsabilização dos profissionais. As escolas foram direcionadas a publicar seus resultados em suas páginas oficiais, tendo o acompanhamento dos pais, estudantes e comunidade em geral. Além disso, os resultados das avaliações externas passaram a compor a média final dos educandos para fins de aprovação ou retenção.

O controle e fiscalização das AEC também foram realizados pelos docentes titulares de cargo, os quais tiveram a prerrogativa de supervisionar, acompanhar e avaliar a execução das referidas atividades (PORTUGAL, 2006), o que poderia instigar a rivalidade entre os profissionais (docentes titulares e profissionais das AEC) que atuavam numa mesma unidade escolar.

\section{Considerações finais}

RPGE - Revista on line de Política e Gestão Educacional, Araraquara, v. 22, n. esp.1, p. 223-243, mar., 2018. 
Considerando a gestão do PME e PETI como os processos pelos quais foram operados, destaca-se três aspectos para efeito de finalização desta reflexão: os fins declarados como justificativos para os Programas; o papel destinado à escola e por fim o agente responsável por sua operacionalização.

O primeiro, se refere aos fins que condicionaram a própria criação desses programas: a diminuição das desigualdades educacionais. Fins equivalentes que se buscou alcançar por meio de processos e lógicas deveras distintas.

O PME apresentou caráter compensatório e focalizado, destinado a escolas de baixo Ideb e/ou situadas em regiões de vulnerabilidade social. Já o PETI, de cunho universal, foi ofertado a todos os educandos portugueses de educação pré-escolar e de $1^{\circ}$ ciclo, sendo facultativa apenas as AEC.

Com relação ao currículo da educação em tempo integral, no Programa brasileiro, a ampliação da jornada escolar dos educandos decorreu de oficinas diversificadas e aleatórias ofertadas no contraturno escolar em qualquer espaço da comunidade. Em Portugal, o PETI, com funcionamento no espaço escolar, promoveu o aumento da carga horária das disciplinas do currículo formal e agregou, restritamente, a oferta das AEC, ou seja, a proposta do PETI pautou-se na oferta de "mais escola", numa perspectiva de "hiperescolarização".

O segundo aspecto a considerar, no que se refere à gestão dos dois Programas, considera o papel da escola na consecução dos fins estabelecidos: em ambos restrito à execução do previsto por agências governamentais. Mais precisamente, no PME, foi atribuída à escola a responsabilidade por captar na comunidade voluntários em condições de oferecer atividades socioeducativas para crianças e jovens de regiões pobres e vulneráveis. Acredita-se que o esforço de tais escolas não deva ter sido pequeno, ainda que se conte com o compromisso da comunidade escolar, sua luta pela sobrevivência tende a não deixar muito espaço para o voluntariado. Coube ainda à escola, a busca por outros espaços físicos para o funcionamento do PME.

No PETI, a escola passou a dividir a responsabilidade pela execução da política, com as entidades promotoras, que passaram a desempenhar funções públicas e educativas. Tais entidades passaram a participar do processo de seleção dos profissionais, disponibilizar materiais e equipamentos necessários à efetivação das AEC, além de inspecionar os resultados alcançados pelo Programa.

Por último, destaca-se os sujeitos responsáveis pela condução das atividades nos Programas: no PME as oficinas foram conduzidas por monitores voluntários 
(oficineiros), não sendo obrigatória a formação/ habilitação para atuação no ensino fundamental; no PETI previu-se a contratação de professores formados para exercer suas atribuições no $1 .^{\circ}$ Ciclo e/ou profissionais/ técnicos habilitados (músicos, dançarinos, atores de teatro) para atuação nas AEC.

No PME, os voluntários foram ressarcidos conforme o número de turmas monitoradas, sendo o pagamento destinado para despesas de alimentação e transporte. Já o PETI, embora previsse um salário mais alto aos profissionais, promoveu uma diferenciação entre a remuneração dos docentes e técnicos das AEC.

Ambos os Programas previram a "participação" de segmentos do setor privado na sua execução. No caso do Brasil a ampliação da jornada escolar derivou exclusivamente da presença deste segmento na forma de atividade voluntária.

Não é demais associar o estímulo a atividades voluntárias com o perfil demandado pelas empresas, as quais segundo Silva e Souza $(2009,793)$, "têm orientado que, no curriculum vitae de um profissional apto à empregabilidade, não pode faltar a menção ao desenvolvimento de uma atividade voluntária de interesse social”.

Por outro lado, a desprofissionalização da atividade educacional, mesmo quando desenvolvida em ambiente não formal, como estratégia governamental para atender aos mais pobres e aos mais vulneráveis não é novidade na educação brasileira, conforme atesta o modelo de atendimento em creches e para estudantes com deficiência, o qual pressupunha a atuação de filantropos e voluntários.

Dialogando com essa lógica, a ampliação da jornada, ao pressupor o setor privado, e ainda na condição de voluntário, expressa a desresponsabilização do Estado para com sua própria iniciativa e exemplifica a tendência identificada por Adrião (2017) de alteração no papel do Estado em um contexto de concentração da riqueza.

A filantropia e o voluntariado passam a integrar um novo mercado, em muitos casos induzido e criado pelo próprio Estado.

Com relação ao PETI, embora o governo português tivesse direcionado para que as autarquias se tornassem responsáveis por desencadear o processo de implantação e efetivação do Programa, admitiu-se a presença do setor privado e/ ou IPSS por meio do estabelecimento de contratos de ação pública, numa lógica muito peculiar à mercadológica.

Propagou-se a ideia de que esse serviço público (para todos) não deveria ser garantido exclusivamente pelo Estado, mas também por entidades privadas, por meio do princípio da subsidiariedade.

RPGE - Revista on line de Política e Gestão Educacional, Araraquara, v. 22, n. esp.1, p. 223-243, mar., 2018. 
A educação em tempo integral poderá favorecer a diminuição das desigualdades educacionais, desde que formulada e estruturada com recursos suficientes para alterar as condições de oferta da educação tal como se encontra.

Significa considerar que a diminuição das desigualdades educacionais, ainda que não decorra exclusivamente da atuação das e nas escolas, tem na melhoria dessas atuações fator fundamental para seu enfretamento. Este, por sua vez, apenas quando considerado elemento de efetivação do direito à educação e portanto, como compromisso do Estado para com as novas e mais vulneráveis gerações, poderá ter efetividade.

\section{REFERÊNCIAS}

ADRIÃO, T. A privatização da educação básica no Brasil: considerações sobre a incidência de corporações na gestão da educação pública. In Araújo, L e Pinto, J. M. R (orgs). Público x privado em tempos e crise. São Paulo: Fundação Lauro Campos e Fineduca. 2017. p.16-37.

ADRIÃO, T.; PERONI, V. (Orgs.). O público e o privado na educação: interfaces entre Estado e sociedade. São Paulo: Xamã, 2005.

BRASIL. Lei no 9.394, de 20/12/1996. Lei de Diretrizes e Bases da Educação Nacional. Diário Oficial da União, Brasília, 23 dez. 1996, Seção I, p. 27833-27841.

BRASIL. Decreto no 6.094, de 24 de abril de 2007. Dispõe sobre a implementação do Plano de Metas Compromisso Todos pela Educação. Brasília, DF, 2007a.

BRASIL. Portaria Normativa n. ${ }^{\circ} 17$, de 24/04/2007. Institui o Programa Mais Educação. Diário Oficial da União, Brasília, 26 abr. 2007b, Seção 1, p. 5-6.

BRASIL. Ministério da Educação. Orientações gerais para elaboração do Plano de Ações Articuladas (PAR) dos municípios. Versão revisada e ampliada. Brasília, DF, nov. 2009.

BRASIL. Decreto $n^{\circ} 7.083$, de 27 de janeiro de 2010. Dispõe sobre o Programa Mais Educação. Diário Oficial da União, Brasília, 27 jan. 2010, Seção 1, p. 2.

BRASIL. Programa Mais Educação Passo a Passo. Brasília, MEC, 2013. Disponível em:

$<$ http://portal.mec.gov.br/index.php?option=com_docman\&view=download\&alias=816 8-e-passo-a-passo-mais-educacao-18042011-pdf\&category_slug=junho-2011pdf \&Itemid=30192>. Acesso em: 8 set. 2017.

CAVALIERE, A. M. Escola Pública de Tempo Integral no Brasil: filantropia ou política de Estado? Educ. Soc. Campinas, v. 35, nº 129, p. 1205-1222, out./dez., 2014. 
FARIA, M. D. P. L. de. Escola a Tempo Inteiro: da fase de implementação à fase de estabilização. 2010. 239f. Dissertação (Mestrado em Educação), na área de especialização em Administração Escolar, Universidade do Minho, Braga, 2010.

JESUS, A. C. de. ; BORGES, W. S. C. A ampliação do tempo escolar nas escolas públicas. Itinerarius Reflectionis, Goiânia, v. 12, n. 1, 2016.

LOPES, L. de C.; ARAÚJO, J. C. Avaliação do Programa Mais Educação na Rede Municipal de Fortaleza: a realidade das escolas da Regional V. In: XVI ENDIPE Encontro Nacional de Didática e Práticas de Ensino - UNICAMP. Campinas, 2012.

MOURAZ, A.; VALE, A.; MARTINS, J. Atividades de enriquecimento curricular: o difícil equilíbrio entre a resposta social e a qualidade educativa. Configurações, vol. 10, 2012, p. 123-136.

PARO, V. H. Administração Escolar: uma introdução crítica. $9^{a}$ ed. São Paulo: Cortez, 2000.

PARO, V. H. crítica da Estrutura da Escola. São Paulo: Cortez, 2011.

PASTORINI, A. O círculo "maldito" da pobreza no Brasil: a mistificação das “novas" políticas sociais. Tese (doutorado). UFRJ: Rio de Janeiro, 2002.

PIRES, C. Escola a Tempo Inteiro: problematização de um "modelo" de implementação. In: REIS, C. S.; NEVES, F. (Coord.), Livro de Atas do XI Congresso da Sociedade Portuguesa de Ciências da Educação (IV Vol.). Guarda: Instituto Politécnico da Guarda, 2011.

PIRES, C. Escola a Tempo Inteiro - Contributos para análise de uma política pública de educação. Santo Tirso (Portugal): $1^{\mathrm{a}}$ ed. De Facto Editores, 2014.

PORTUGAL. Despacho no 12.591, de 16 de junho de 2006. Estabelece o Programa Escola a Tempo Inteiro. Diário da República, II série, n. ${ }^{\circ}$ 115, 16 de jun. 2006a.

PORTUGAL. CAP - Comissão de Acompanhamento do Programa. Relatório Intercalar de Acompanhamento das AEC - Programa de Generalização do Ensino de Inglês nos $3^{\circ}$ e $4^{\circ}$ Anos e de Outras AEC no $1 .^{\circ}$ Ciclo do Ensino Básico. Lisboa: Ministério da Educação, 2006b.

PORTUGAL. Portaria n ${ }^{\circ}$ 644-A/2015, de 24 de agosto. Diário da República, II série, nº 164 - 24 ago., 2015. Disponível em: <https://dre.pt/application/file/70094310>. Acesso em: 1 nov. 2017.

RODRIGUES, M. de L. A escola pública pode fazer a diferença. Coimbra: Almedina, 2010.

ROSA, V. S. da. O Programa Mais Educação como política pública nacional de educação integral. IX Anped Sul- Seminário de Pesquisa em educação da região Sul, 2012. 
SCHIMONEK, E. M. P. A Autonomia Escolar e o Programa Mais Educação. II Colóquio Internacional de Ciências Sociais- O governo das escolas: atores, políticas e práticas, Braga/ Portugal, 2015. Disponível em: <http://webs.ie.uminho.pt/iicicse/files/ATAS-IICICSE_CS2015.pdf>. Acesso em: 20 set. 2017.

SCHIMONEK, E. M. P. Programas governamentais para educação em tempo integral no Brasil e Portugal: implicações sobre as desigualdades educacionais. Doutorado em Educação, na área de Políticas, Administração e Sistemas Educacionais, Universidade Estadual de Campinas- Unicamp, Campinas, 2017.

SILVA, M. V.; SOUZA, S. A. de. Educação e responsabilidade empresarial: "novas" modalidades de atuação da esfera privada na oferta educacional. Educ. Soc., Campinas, v. 30, n. 108, p. 779-798, out., 2009.

\section{Como referenciar este artigo}

SCHIMONEK, Elisangela Maria Pereira.; ADRIÃO, Theresa. A gestão dos programas Mais Educação e Escola a Tempo Inteiro: uma análise de políticas para educação em tempo integral. Revista on line de Política e Gestão Educacional, Araraquara, v. 22, n. esp.1, p. 223-243, mar., 2018. E-ISSN:1519-9029.

Submetido em: 04/10/2017

Aprovado em: 14/12/2017 